\title{
RelB regulates the homeostatic proliferation but not the function of Tregs
}

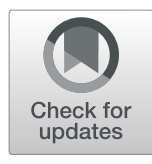

\author{
Shuping Zhou ${ }^{*}$, Weiwei Wu' ${ }^{2}$ Zhaoxia Wang ${ }^{1}$, Zhaopeng Wang ${ }^{1}$, Qinghong Su', Xiaofan Li', Yong Yu', \\ Weidong Zhang ${ }^{1}$, Mingzhao $\mathrm{Zhu}^{2}$ and Wei Lin ${ }^{1 *}$
}

\begin{abstract}
Background: RelB, a member of the NF-KB family, plays a critical role in the development of T cells. However, the role of RelB in Foxp3 ${ }^{+}$regulatory T cells (Tregs) remains controversial.

Results: Using a bone marrow chimeric mouse model, we demonstrated that the expansion of Foxp3 ${ }^{+}$Tregs in vivo could be mediated by extrinsic mechanisms. RelB plays an important role in inhibiting the homeostatic proliferation of Tregs, but not their survival. Even with the heightened expansion, RelB ${ }^{-/-}$Treg cells displayed normal suppressive function in vitro. Among the expanded populations of Treg cells, most were nTreg cells; however, the population of iTregs did not increase. Mechanistically, RelB seems to regulate Treg proliferation independently of the signal transducer and activator of transcription 5 (STAT5) pathway.
\end{abstract}

Conclusions: These data suggest that RelB regulates Treg proliferation independently of the STAT5 pathway, but does not alter the function of Tregs. Further studies are warranted to uncover such mechanisms.

Keywords: RelB, Treg, Cells proliferation, STAT5

\section{Background}

$\mathrm{CD}^{+} \mathrm{CD}^{+} 5^{+}$regulatory $\mathrm{T}$ cells (Treg) are of central importance for the maintenance of peripheral tolerance and the regulation of cellular immune responses. Tregs is divided into two groups based on their origin and phenotypic characteristics: naturally occurring Tregs (nTregs) from the thymus and induced Tregs (iTregs) from the periphery [1-4]. Foxp3 is an important marker [5] and a key transcription factor that regulates the differentiation and function of Tregs. The homeostasis of Treg cells is important for sustaining their function and maintaining the immune balance. Appropriate Treg homeostasis at the periphery plays a crucial role in the maintenance of selftolerance. Disturbances in this balance are frequently associated with autoimmune diseases. Unlike the homeostasis of naive conventional $\mathrm{T}$ cells, Treg homeostasis at the

\footnotetext{
*Correspondence: shupzhou718@163.com; Linw1978@163.com

${ }^{1}$ Institute of Basic Medicine, Shandong Provincial Hospital Affiliated to Shandong First Medical University, Jinan 250062, China

Full list of author information is available at the end of the article
}

periphery is a much more dynamic process, and its underlying molecular mechanisms has been one of the important topics in this field.

The NF- $\mathrm{KB}$ signaling pathways, including the canonical and non-canonical NF- $\mathrm{kB}$ signaling pathways, play an important role in the development and maintenance of the peripheral Treg population $[6,7]$. RelB is an important transcription factor of non-canonical pathway of NF$\kappa \mathrm{B}$ family that regulates diverse immune and inflammatory responses [8-10]. Previous studies showed that germline deletion of RelB caused perturbation in the $\mathrm{T}$ cell repertoire, which suggests that RelB is required for $\mathrm{T}$ cell development [11-13]. However, the role of RelB in the development of Foxp $3^{+}$regulatory T cells (Tregs) remains controversial. A study reported that the percentage of Foxp $3^{+}$Tregs was increased in RelB deficient mice, but the absolute number of $\mathrm{CD} 4^{+} \mathrm{Foxp}^{+}$Tregs is comparable to that of $\mathrm{RelB}^{+/-}$mice [14]. By contrast, other studies reported normal $\mathrm{T}$ cell development in $\operatorname{RelB}^{-/-}$mice $[15,16]$. These differences may occur since 
Treg development is influenced by stromal cells of lymphoid origin, and RelB is involved in the regulation of stromal cells [17-22]. Additionally, Foxp $3^{+}$Tregs from $\operatorname{RelB}$ deficient mice up-regulated certain activation markers and effector molecules on the cell surface [20]. Furthermore, the intrinsic role of RelB signaling in regulating the homeostasis and competitive fitness of Tregs was also identified [23]. However, the inhibitory function of RelB on effector $\mathrm{T}$ cells is not different from the role of Tregs in wild-type mice [20]. Currently, the role of RelB in the generation and suppressive activities of Foxp $^{+}$Tregs is still not clear.

Our study used chimeric mouse models with bone marrow cells from wild-type (WT) or RelB deficient mice to study the role of RelB in regulating the proliferation and function of Tregs and their subsets. We also investigated the possible mechanisms of RelB on the proliferation of Tregs to demonstrate the role of RelB in the homeostatic proliferation and function of Treg.

\section{Results}

RelB influences the frequency of thymic and peripheral Treg cells

To study the role of RelB on the regulation of Tregs, we first measured the percentage of Treg cells in the thymus and spleens of $\mathrm{RelB}^{-/-}$mice. The percentage of $\mathrm{CD}^{+}{ }^{+}$Foxp $^{+} \mathrm{T}$ cells (Tregs) out of the total population of $\mathrm{CD}^{+} \mathrm{T}$ cells was reduced in the $\mathrm{RelB}^{-1-}$ thymus (Fig. 1a). By contrast, the proportion of Tregs out of the total $\mathrm{CD}^{+} \mathrm{T}$ cell population in the spleen of $\mathrm{RelB}^{-/-}$ mice was increased (Fig. 1b). Similar to previous reports [19, 24-26], RelB ${ }^{-/-}$mice have reduced thymic cellularity and markedly fewer medullary thymic epithelial cells, which provide a delicate microenvironment for the negative selection and induction of Treg cells.

We generated bone marrow chimeric mice to determine the role of RelB in the regulation of Tregs in vivo. Six-week-old CD45.1 mice were irradiated with (Cobalt60) Co60 at (a dose of 10 Gy). The next day, $5 \times 10^{6}$ donor bone marrow cells from WT or $\operatorname{RelB}^{-/-}$(CD45.2) mice were intravenously transferred. After 8 to 12 weeks, the percentages of Treg cells from the thymus and spleen of the chimeric mice were analyzed by flow cytometry. The proportion of Tregs in the thymus and spleen of the mice received bone marrow cells from $\mathrm{RelB}^{-/-}$mice, was higher than those of animals that received bone marrow cells from WT mice (Figs. 2a-b, $P$ $<0.001)$. Excluding the effect of stromal cells and epithelial cells on Tregs, RelB deficiency enhanced the proportion of Treg cells in the spleen and thymus.

\section{RelB controls the development of $n$ Treg in the bone marrow chimeric mouse model}

Regulatory $\mathrm{T}$ cells can be divided into two groups: naturally occurring Tregs (nTregs) from the thymus and induced Tregs (iTregs) from the periphery. To determine which groups of cells in the peripheral Treg were affected by RelB deficiency, we further measured the
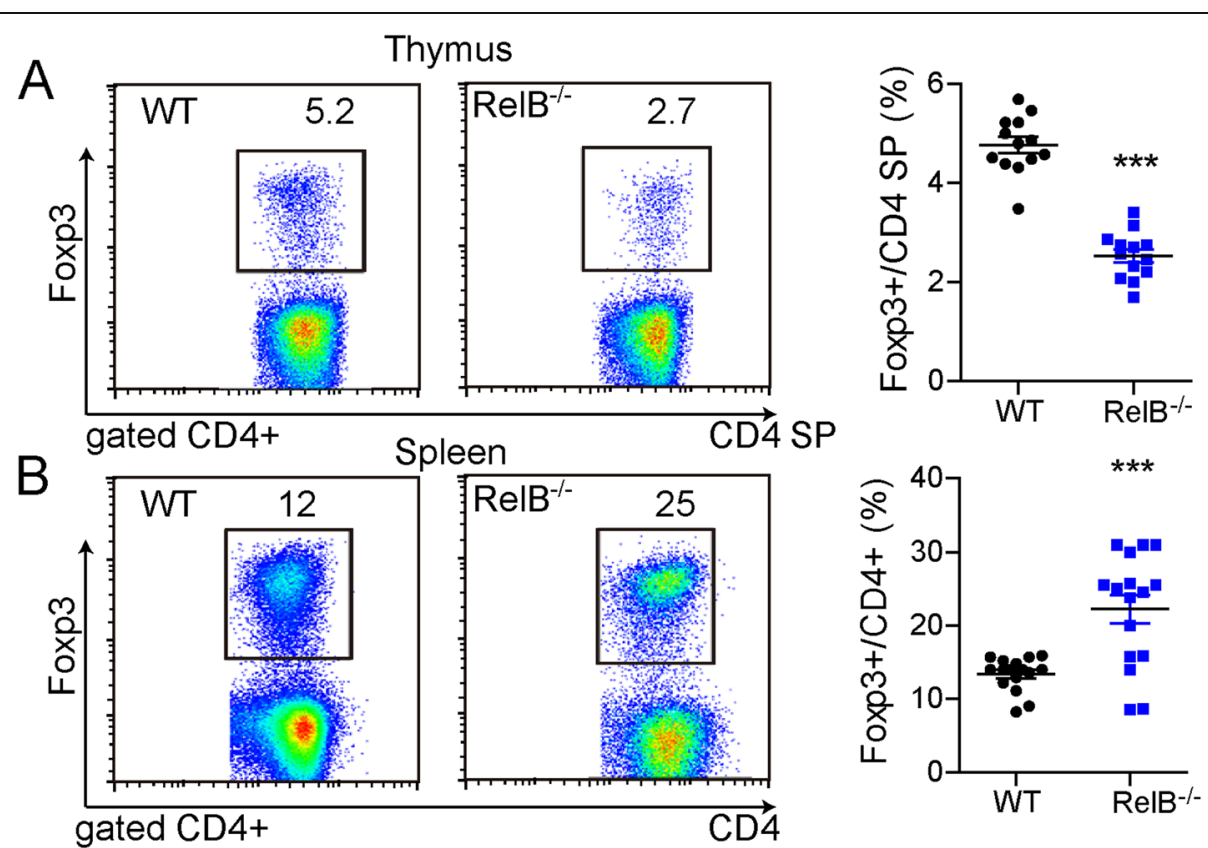

Fig. 1 Decreased thymic but increased peripheral Treg cell frequency in RelB deficient mice. CD4 ${ }^{+} T$ cells were obtained from the thymus and spleen of 6 weeks old WT or RelB ${ }^{-1-}$ mice, and were assayed by FACS. a Thymic Treg FACS plot and statistic analysis. b Splenic Treg FACS plot and statistic analysis. ${ }^{* *} P<0.001$ 

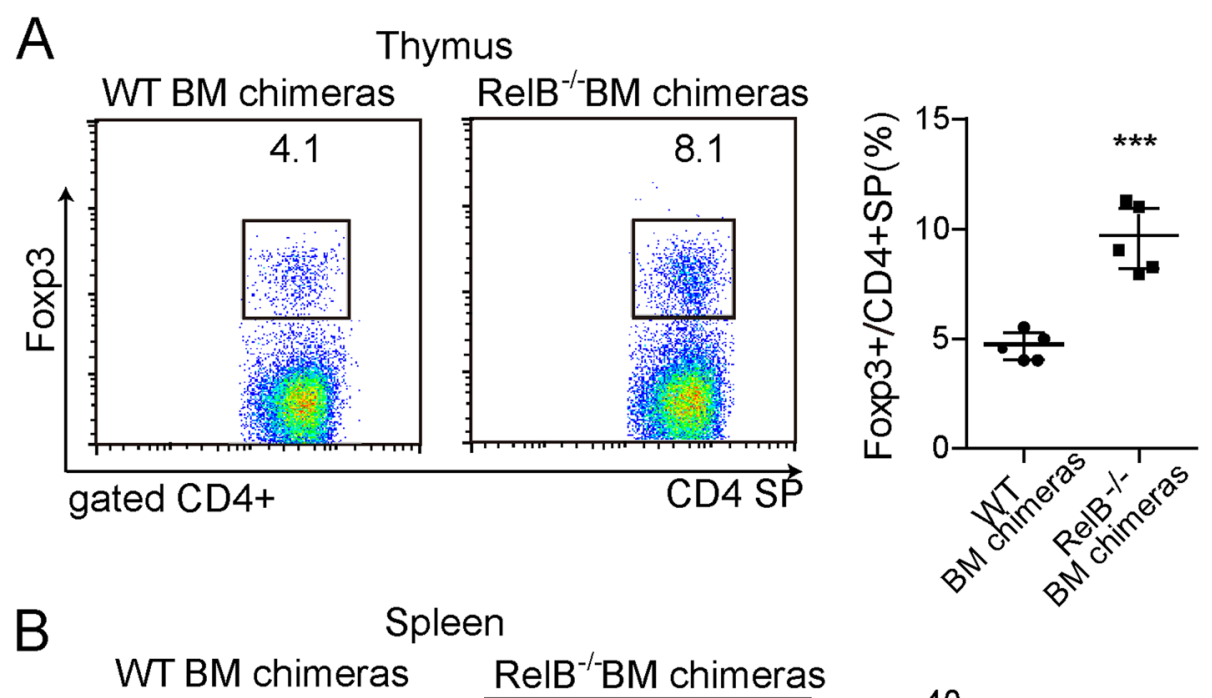

Spleen
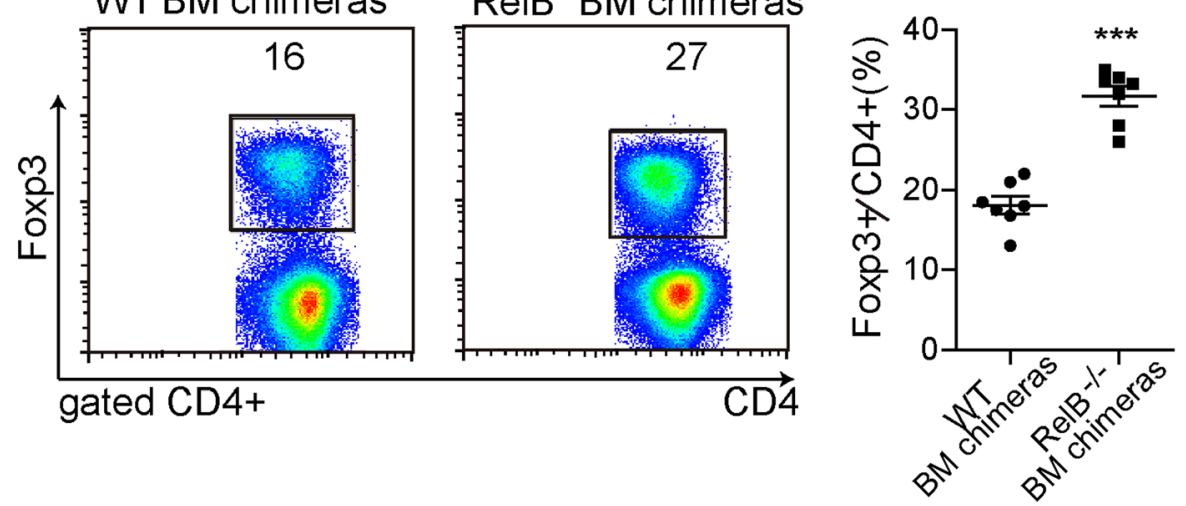

Fig. 2 Increased thymic and peripheral Treg cell frequency in RelB ${ }^{-1-}$ bone marrow chimeric mice. The bone marrow from 6 weeks old WT or RelB ${ }^{-1-}$ mice were transferred to the lethal irradiated mice. 8 weeks later, the mice were assayed for thymic and splenic Treg frequency by FACS. a Thymic Treg FACS plot and statistic analysis. b Splenic Treg FACS plot and statistic analysis. ${ }^{* *} P<0.001$

expression of Helios, a marker of nTregs. After bone marrow cells from WT or RelB ${ }^{-/-}$mice were transferred to the lethally irradiated mice for 8 weeks, we measured the expression of Helios, and Foxp3 among Tregs by flow cytometry. There was a greater population of Fox$\mathrm{P3}^{+}$Helios $^{+}$Tregs (nTregs) among mice that received bone marrow transplants from $\operatorname{RelB}^{-/-}$mice compared to those that received a transplant from WT mice (Fig. 3a). At the same time, we also assessed the ability of the naive conventional $\mathrm{T}$ cells and the thymic Treg precursor cells from $\mathrm{RelB}^{-/-}$bone marrow chimeric mice or WT mice to induce iTregs. We found that the naive $\mathrm{CD}^{+}{ }^{+} \mathrm{T}$ cells from $\mathrm{RelB}^{-/-}$bone marrow chimeric mice had a lower capability to form Foxp $3^{+}$Tregs compared to those from WT bone marrow chimeric mice (Fig. 3b). However, the $\mathrm{CD} 4^{+} \mathrm{CD} 8^{-} \mathrm{CD} 25^{+} \mathrm{CD} 69^{+} \mathrm{CD} 24^{+}$thymic Treg precursor cells from $\mathrm{RelB}^{-/-}$bone marrow chimeric mice can induce Foxp $3^{+} \mathrm{T}$ cells compared to those from WT bone marrow chimeric mice (Fig. 3c). These results indicated that RelB deficiency only influences the development of nTregs in the bone marrow chimeric mouse model. Thus, RelB plays a different role in the regulation of nTregs and iTregs.

RelB negatively regulates the homeostatic proliferation of Treg by Treg-extrinsic factors

RelB deficiency enhances the frequency of Tregs in the spleen (Fig. 4a, left panel). To determine whether the increased number of Tregs in the spleens of $\mathrm{RelB}^{-/-}$bone marrow chimeric mice was caused by proliferation, we analyzed the expression of Ki67, a marker of proliferation for $\mathrm{CD} 4^{+} \mathrm{T}$ cells. Our results showed that the population of $\mathrm{Ki}^{2} 7^{+}$Tregs from $\mathrm{RelB}^{-/-}$bone marrow chimeric mice was higher than the population from WT bone marrow chimeric mice. However, the percentage of $\mathrm{Ki}_{67}{ }^{+} \mathrm{CD} 4^{+} \mathrm{Foxp}^{-} \mathrm{T}$ cells from $\mathrm{RelB}^{-/-}$bone marrow chimeric mice was not different from that of WT bone marrow chimeric mice (Fig. 4a). At the same time, we isolated the splenic Tregs from WT and $\mathrm{RelB}^{-/-}$bone marrow chimeric mice and cultured them in vitro to detect the survival of $\mathrm{T}$ cells at $6,24,48 \mathrm{~h}$. We analyzed the survival of following populations: WT Tregs, RelB ${ }^{-/-}$ 

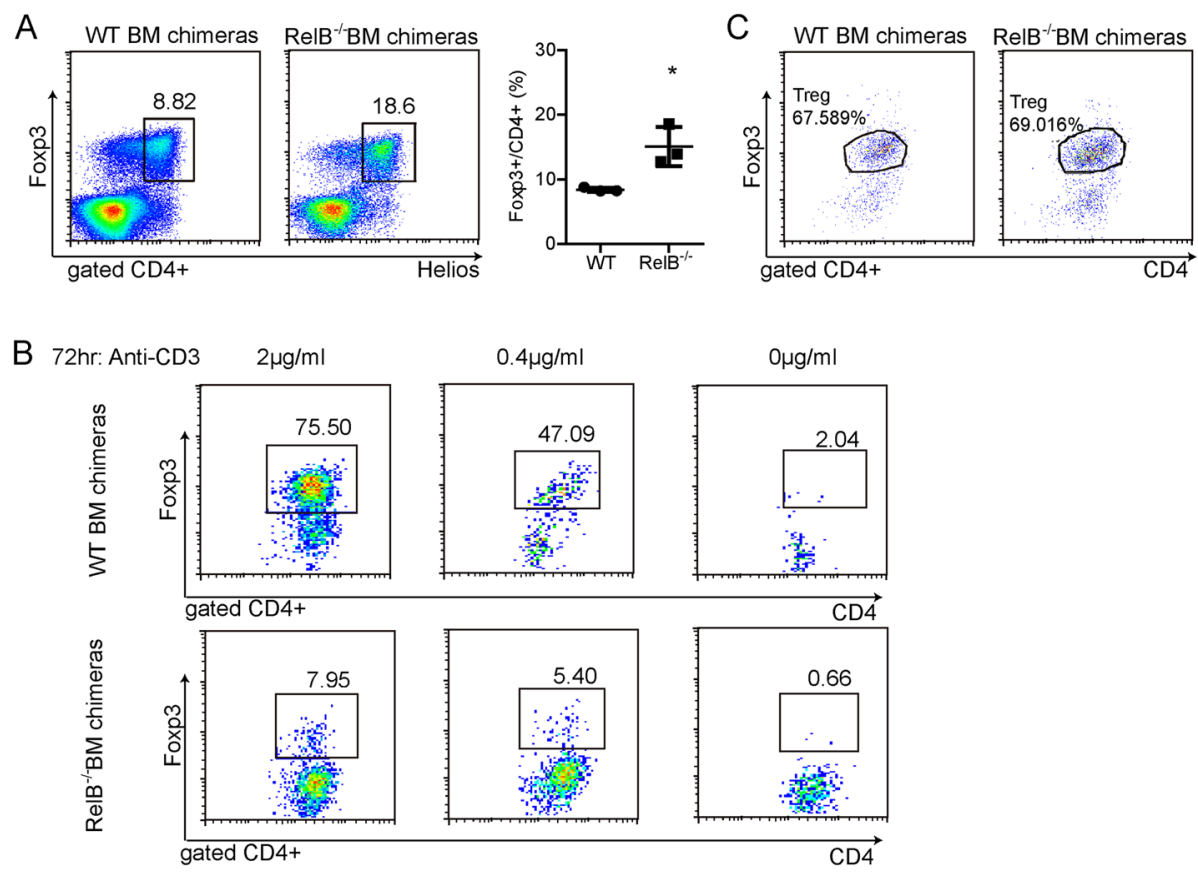

Fig. 3 RelB controls nTreg but not iTreg development. The bone marrow from 6 weeks old WT or RelB ${ }^{-1-}$ mice were transferred to the lethal irradiated mice. 8 weeks later, the mice were assayed for splenic Treg frequency and helios expression by FACS (a) and the naive CD4 ${ }^{+}$T cells were sorted by FACS to induce the iTreg with anti-CD3 antibody for $72 \mathrm{~h}$ to detect the Foxp3 expression (b). $\mathbf{c}$ Treg precursor cells $\left(\mathrm{CD} 4^{+} \mathrm{CD} 8^{-} \mathrm{CD} 25^{+} \mathrm{CD} 69^{+} \mathrm{CD} 24^{+}\right)$ into mature Treg cells after IL-2 treatment were detected by FACS

Treg, WT CD4 $4^{+} \mathrm{CD} 25^{-} \mathrm{T}$ cells (non-Tregs), and RelB ${ }^{-/-}$ $\mathrm{CD} 4^{+} \mathrm{CD} 25^{-} \mathrm{T}$ cells $\left(\right.$ RelB $^{-/-}$non-Tregs) and found no difference in the survival of these $\mathrm{T}$ cells (Fig. $4 \mathrm{~b}$ ). $\mathrm{RelB}^{-1-}$ Tregs display normal survival in vitro.

Furthermore, we also measured the rate of $\mathrm{CD}^{+}{ }^{+} \mathrm{T}$ cell proliferation in vivo. Splenic $\mathrm{CD} 4^{+} \mathrm{T}$ cells from WT or $\mathrm{RelB}^{-/-}$mice were sorted and labeled with carboxyfluorescein succinimidyl ester (CFSE) respectively, and then were transferred them to the host mice, which were irradiated with a 5 Gy dose of Co60. To our disappointment, Treg cells from $\mathrm{RelB}^{-/-}$bone marrow chimeric mice showed a decreased rate of proliferation compared with WT bone marrow chimeric mice (Figs. 4c, d). The above results show that the proliferation of $\mathrm{RelB}^{-/-}$Tregs may be regulated by exogenous factors.

We also want to know if the function of Treg cells from $\mathrm{RelB}^{-/-}$mice was normal. WT or $\mathrm{RelB}^{-/-}$Tregs were isolated and mixed with CFSE-labeled naive conventional $\mathrm{CD}_{4}^{+} \mathrm{T}$ cells $\left(2 \times 10^{5}\right)$ at different ratios. AntiCD3 $(1 \mu \mathrm{g} / \mathrm{mL})$ and anti-CD28 $(1 \mu \mathrm{g} / \mathrm{mL})$ antibodies were used to stimulate $\mathrm{T}$ cell proliferation. Three days later, we measured $\mathrm{T}$ cell proliferation using flow cytometry. The results indicated that the WT and $\mathrm{RelB}^{-/-}$ Tregs displayed comparable suppressive function in vitro, and RelB did not influence the function of Tregs (Fig. 4e).
RelB ${ }^{-/}$Tregs did not display higher levels of phosphorylated signal transducer and activator of transcription 5 (STAT5) than WT Tregs in vitro

Signal transducer and activator of transcription 5 (STAT5) is an important transcription factor for maintaining the expression and stability of Treg. The level of phosphorylated STAT5 is correlated with the proliferation of Treg cells. So we measured the levels of phosphorylated STAT5 (pSTAT5) in Tregs from WT or $\mathrm{RelB}^{-/-}$mice in vitro. Tregs were isolated from $\mathrm{RelB}^{-/-}$ mice and cultured in 24-well plates. After stimulation with different concentrations of IL-2 (0, 2, and $10 \mathrm{ng})$ for $30 \mathrm{~min}$, the cells were harvested and the level of phosphorylated STAT5 was measured by flow cytometry. We did not detect higher pSTAT5 levels in Tregs from $\operatorname{RelB}^{-/-}$mice compared to WT mice (Fig. 5). RelB seems to regulate the proliferation of Treg independently of the STAT5 pathway.

\section{Discussion}

In this study, we demonstrated that RelB deficiency exerts a profound effect on the proliferation of Foxp $3^{+}$ Tregs, and markedly expands the Treg pool in the periphery. RelB, a component of the NF- $\mathrm{kB}$ complex of transcription factors, is a critical regulator of differentiation among medullary thymic epithelial cells and 


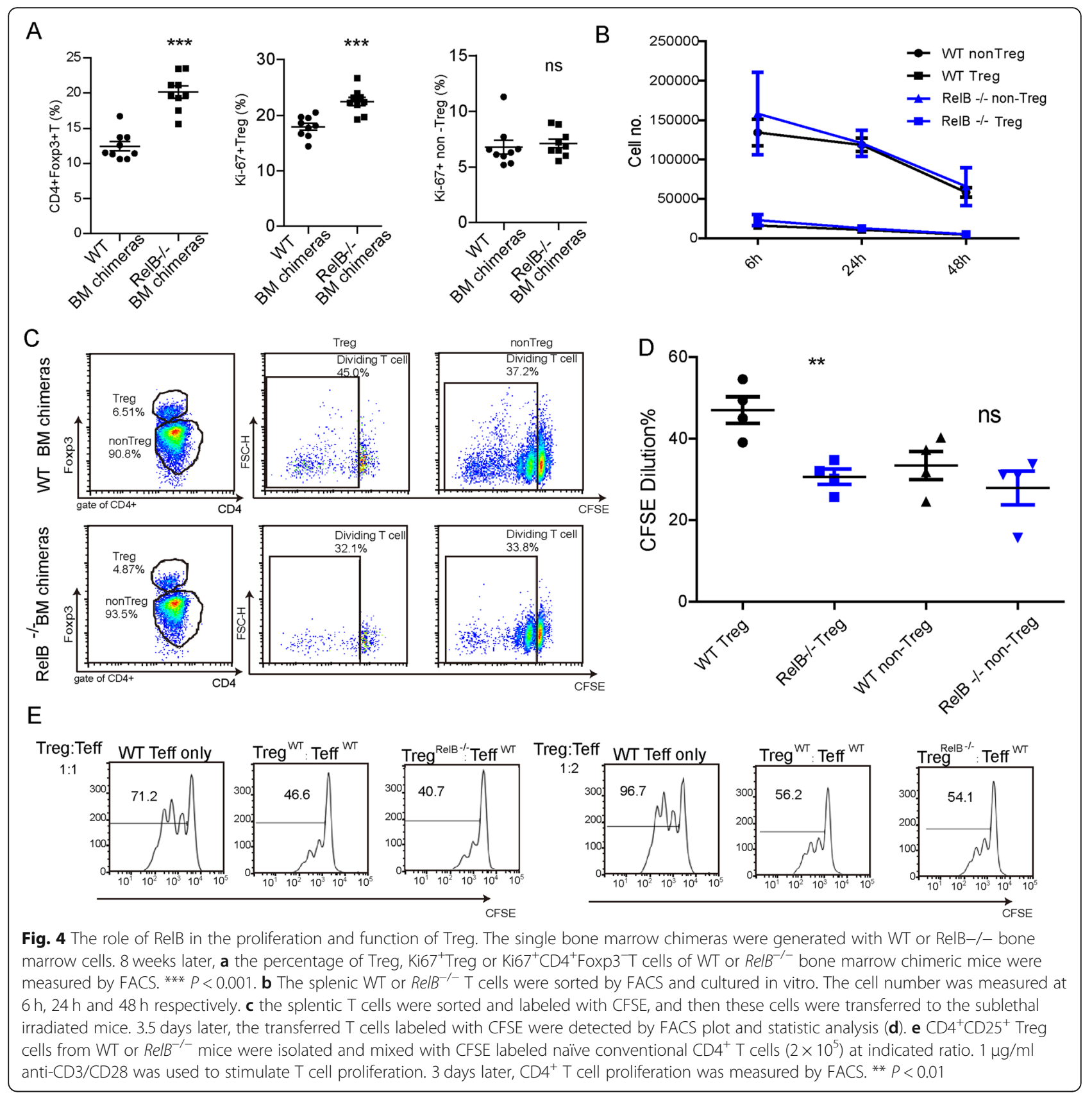

hematopoietic cells $[15,18,19]$. Besides decreased thymic cellularity, $\operatorname{RelB}^{-/-}$mice had the following abnormal phenotypes: multifocal, mixed inflammatory cell infiltration in several organs, myeloid hyperplasia, splenomegaly due to extramedullary haematopoiesis, and a decreased population of thymic dendritic cells. RelB deficiency decreases the population of Tregs in the thymus but increases the thymus Treg populations of bone marrow chimeric mice. These findings indicate that RelB may play a critical role in regulating Treg cell development and homeostasis by influencing the function and status of non-hematopoietic cells. RelB deficiency did not influence the proliferation and survival of Tregs directly in our experiments nor other reports [20]. RelB may control the development and proliferation of Tregs through extrinsic cell populations [11, 12, 27-31]. Dendritic cells (DC) and Foxp3 $3^{-} \mathrm{T}$ cells were confirmed to regulate the expansion of Tregs through RelB-dependent secretion of cytokines secretion [32,33]. The effect of the NF- $\mathrm{kB}$ pathway on $\mathrm{T}$ cell activation is largely driven through the activation of DC. Thus, the development of Tregs in $\mathrm{RelB}^{-/-}$mice was influenced by exogenic factors. Additionally, mice deficient in the non-canonical NF- $\mathrm{kB}$ component gene NF-kB 2 (p100), which inhibits 


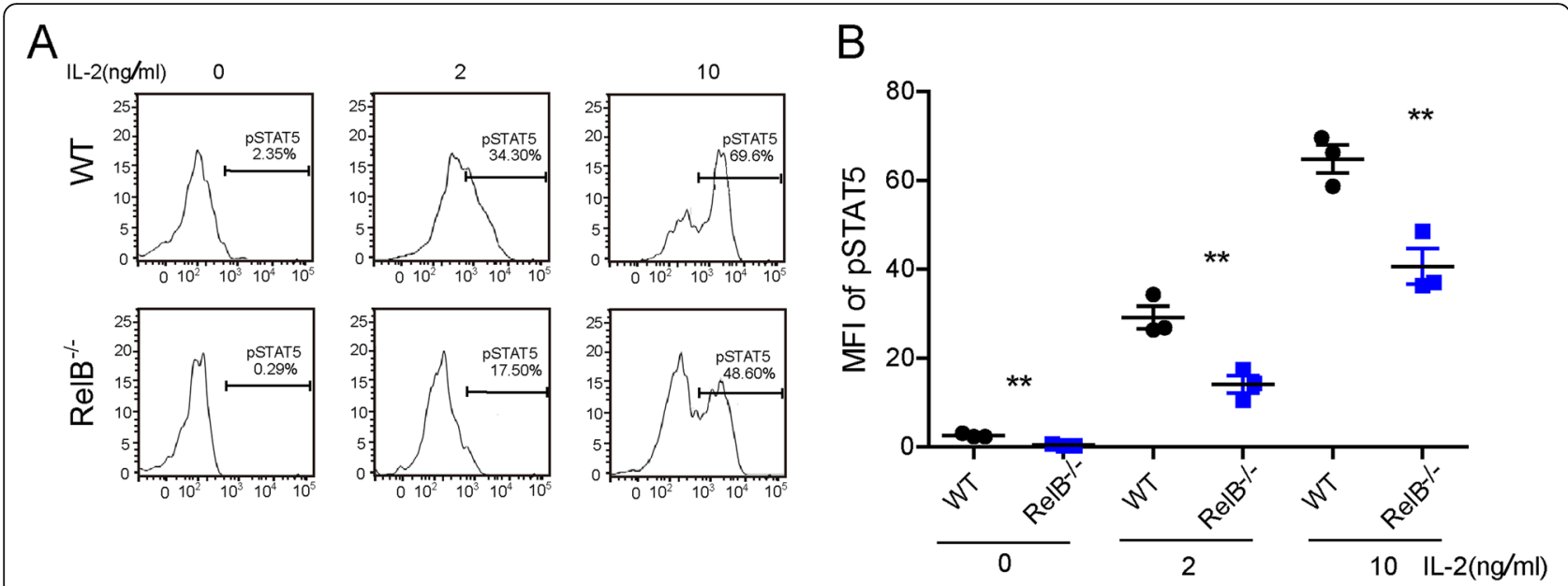

Fig. 5 The expression of phosphorylated STAT5 in RelB ${ }^{-/-}$Treg cells. a The T cells from RelB ${ }^{-1-}$ and WT bone marrow chimeras were isolated and stimulated with indicated concentration of recombinant IL-2 in vitro for $30 \mathrm{~min}$, then the phosphorylation of STAT5 was measured by FACS. $\mathbf{b}$ Statistic analysis of mean fluorescence index of PSTAT5 at different conditions. ${ }^{*} P<0.01$

RelB activation and participates in RelB nuclear activity, showed normal thymic development and suppressive function of Tregs. However, they had higher populations of peripheral "effector-phenotype" Tregs (eTregs) [23, $34,35]$. This demonstrates that with p100 inhibition of RelB possibly maintaining the suppressive functions of Treg. Therefore, RelB may be a negative regulator but not the master regulator of Treg development.

Furthermore, our study showed the increased Tregs in $\mathrm{RelB}^{-/-}$bone marrow chimeric mice were primarily nTregs rather than iTregs. These results suggest that RelB may control the homeostasis of nTregs but not iTregs. However, a small proportion of $\mathrm{RelB}^{-/-} \mathrm{CD} 4^{+} \mathrm{T}$ cells were induced to be Foxp $3^{+}$Tregs compared with WT CD4 ${ }^{+} \mathrm{T}$ cells. This indicates the role of RelB in induced Foxp $3^{+}$Treg. Further studies are undoubtedly required to explore the mechanism of RelB on the regulation of nTregs and iTregs.

Additionally, RelB may regulate the transcription of genes involved in the generation of Tregs [20]. Tregs in $\mathrm{RelB}^{-/-}$mice upregulated certain activation markers and effector molecules on the cell surface, including CTLA4, KLRG1, and TIGIT [20]. Our research and other studies $[14,20,33]$ have found that $\operatorname{RelB}^{-/-}$Tregs showed similar suppressive activities as their WT counterparts. The deletion of RelB did not influence the proliferation of Tregs in vitro, but increased the proliferation of Tregs in vivo. These data suggest that the role of RelB in the function and proliferation of FoxP3 ${ }^{+}$Tregs. Therefore, the molecular mechanismof RelB on Tregs remain to be studied in the future.

Furthermore, we found that with IL-2 stimulation, the levels of pSTAT5 in Tregs from $\mathrm{RelB}^{-/-}$mice were not higher than those from WT Treg. RelB deficiency by itself does not affect the Treg functions. Previous reports had shown that the expansion of Foxp $3^{+}$Tregs in $\mathrm{RelB}^{-/-}$mice were mediated primarily by the hyperactivation of FoxP3 ${ }^{-} \mathrm{T}$ effector cells that spontaneously produce increased levels of IL-2, a growth factor for Foxp3 + Tregs [18, 19, 36-39]. IL-2 is an activator of STAT5 signaling [40]. Upon IL-2 stimulation, RelB seems to regulate Treg proliferation independently of the STAT5 pathway. $\operatorname{RelB}^{-/-}$Treg cells may have a weaker response to IL-2 than WT Treg cells. Whether IL-2 promotes the proliferation of $\mathrm{RelB}^{-/-}$Tregs through other factors or pathways requires further investigation.

\section{Conclusions}

Our study identified a critical role for RelB in regulating the homeostasis of Foxp $3^{+}$Tregs. This effect was shown to be mediated by Treg cell-extrinsic mechanisms and occurred independently of STAT5 signaling. The possible endogenous factors that regulate the proliferation of Treg in $\mathrm{RelB}^{-/}$mice need to be identified in future studies. Furthermore, the importance and complexity of RelB in the regulation of the immune system to ensure homeostasis and immune tolerance require further study.

\section{Methods}

\section{Animals}

RelB $^{-/-}$mice and CD45.1 mice (6 weeks of age, female) were gifts from Dr. Y. X. Fu (University of Texas Southwestern Medical Center, Dallas, TX, USA). WT C57BL/ 6 mice ( 6 weeks of age, female) were purchased from Vital River Laboratory Animal Technology (Beijing, China). All mice were housed under specific pathogenfree conditions in the laboratory animal room of Institute of Biophysics, Chinese Academy of Sciences. All animals were housed with a $12 \mathrm{~h}$ light/dark cycle on ventilated racks with corncob bedding. The cage 
temperature was maintained from 68 to 76 degrees Fahrenheit. Five animals were housed in each cage. Animals were fed and given water every day. All procedures were performed in compliance with guidelines for the care and use of laboratory animals and were approved by the ethics committee of the Institute of Biophysics, Chinese Academy of Sciences (Beijing, China) and Shandong Academy of Medical Sciences (Shandong, China).

\section{Bone marrow chimeric construction}

Six-week-old CD45.1 mice were irradiated with a $10 \mathrm{~Gy}$ dose of Co60. The next day, WT or RelB ${ }^{-/-}$(CD45.2) mice were euthanized and bone marrow cells were extracted from the thigh bone to form a single-cell suspension. Donor cells $\left(5 \times 10^{6}\right)$ were intravenously transferred to recipients. Mice were continuously fed sulfamethoxazole and trimethoprim (Bactrim) for 4 weeks starting 1 day before irradiation. Five mice per group were used for experiments. Six to 8 weeks later, mice were euthanized by $\mathrm{CO}_{2}$ inhalation followed by cervical dislocation for thymocyte and splenocyte analysis.

\section{Flow cytometry and antibodies}

Mouse splenocytes and thymocytes were prepared from pooled thymus or spleen. Thymic and splenic cells were pre-incubated with Fc-block before staining with other antibodies. The mouse antibodies used included anti-CD4 (RM4-5, eBioscience); anti-CD8 (53-6.7, eBioscience); anti-CD45.1 (A20, BioLegend), anti-CD45.2 (104, eBioscience); anti-CD25 (PC61.5, eBioscience); anti-CD69 (H1.2F3, eBioscience); anti-CD24 (M1/69, eBioscience); anti-Helios (22F6, eBioscience) before flow cytometry analysis. For intracellular staining of Ki-67 (B56, BD), pSTAT5 (47/Stat5(pY694), BD) and Foxp3 (NRRF-30, eBioscience), cells were fixed and permeabilized with BD Cytofix/Cytoperm ${ }^{\text {Ta }}$ Fixation / Permeabilization Solution Kit $(554,714, \mathrm{BD})$ and stained according to the manufacturer's protocols. The $\mathrm{CD} 4^{+} \mathrm{T}$ cells from the thymus and spleen of WT or $\mathrm{RelB}^{-/-}$mice were analyzed by flow cytometry and gated as shown in the Supplementary Figure 1. The samples were analyzed using a BD LSRFortessa flow cytometer and FlowJo software (Tree Star Inc). All single-cell suspensions from the tissues were stained with Abs diluted in PBS containing 2\% FCS for 30 min on ice.

\section{Adoptive cell-transfer experiments}

The WT and $\mathrm{RelB}^{-/-}$splenic $\mathrm{CD} 4^{+} \mathrm{T}$ cells were labeled with $5.0 \mu \mathrm{M}$ 5- (and 6-) CFSE (Molecular Probes, Inc. Eugene, OR, USA) for $15 \mathrm{~min}$ at $37^{\circ} \mathrm{C}$. Then the cells were washed with PBS twice before re-suspending in PBS. For adoptive transfer, the $\mathrm{CD} 4^{+} \mathrm{T}$ cells $\left(\mathrm{CD} 45.1^{+} \mathrm{CD} 4^{+}\right)$derived from WT or $\left(\mathrm{CD} 45.2^{+} \mathrm{CD} 4^{+}\right)$derived from $\mathrm{RelB}^{-/-}$ mice were respectively transferred into $\mathrm{CD} 45.1^{+} \mathrm{CD} 45.2^{+}$ WT B6 mice intravenously. At 3.5 days after cell transfer, the phenotype of transferred CD45. $1^{+} \mathrm{CD} 4^{+} \mathrm{T}$ cells or $\mathrm{CD} 45.2^{+} \mathrm{CD} 4^{+} \mathrm{T}$ cells in the host spleen was assessed by flow cytometry by gating on live $\mathrm{CD} 4^{+} \mathrm{T}$ cells.

\section{The induction of iTregs from the spleen}

Naive $\mathrm{CD} 4^{+} \mathrm{CD} 25^{-} \mathrm{T}$ cells from WT or $\mathrm{RelB}^{-/-}$splenocytes were sorted using a BD Aria III flow cytometer (BD Biosciences, CA, USA). The purity of $\mathrm{CD} 4^{+} \mathrm{CD} 25^{-}$ $\mathrm{T}$ cells was routinely above $90 \%$, and these cells were cultured in 96-well plates with TGF- $\beta$ ( $5 \mathrm{ng} / \mathrm{mL}$; Peprotech) and IL-2 (50 U/mL; R\&D) stimulation. Three days later, flow cytometry was used to measure the expression of $\mathrm{CD}^{+}{ }^{+}$Foxp $^{+} \mathrm{T}$ cell (iTreg).

\section{Isolation and induction of Treg precursor cells}

Treg precursors were defined as $\mathrm{CD} 4^{+} \mathrm{CD} 8^{-} \mathrm{CD} 25^{+} \mathrm{CD} 69^{+} \mathrm{CD} 24^{+}$cells that were isolated from the thymocytes of WT or RelB ${ }^{-/-}$mice and sorted using a BD Aria III flow cytometer (BD Biosciences, CA, USA). The purity of Treg precursor cells was routinely above $90 \%$. Cells were harvested and stimulated with IL-2 $(50 \mathrm{U} / \mathrm{mL} ; \mathrm{R} \& \mathrm{D})$ for 3 days to induce the Treg phenotype. Single-cell suspensions were collected, stained, and detected using flow cytometry.

\section{The inhibition of Treg on T cells}

WT or $\mathrm{RelB}^{-/-} \mathrm{CD} 4^{+} \mathrm{CD} 25^{+}$Treg cells were isolated and mixed with CFSE-labeled naive conventional $\mathrm{CD} 4^{+}$ $\mathrm{T}$ cells $\left(2 \times 10^{5}\right)$ at different ratios (Treg: conventional $\mathrm{T}=1: 1,1: 2)$. Anti-CD3 $(1 \mu \mathrm{g} / \mathrm{mL})$ and anti-CD28 $(1 \mu \mathrm{g}$ $/ \mathrm{mL}$ ) antibodies were used to stimulate $\mathrm{T}$ cell proliferation. Three days later, $\mathrm{T}$ cell proliferation was measured by flow cytometry.

\section{Statistical analysis}

Flow cytometry data were analyzed with FlowJo (Tree Star) software. Numerical data were processed in Excel (Microsoft) and plotted in Graphpad Prism (Graphpad Software, Inc). Statistical significance was determined using the nonparametric Mann-Whitney $U$ test. ${ }^{*} P<$ $0.05, \quad * * P<0.01$, and ${ }^{* * *} P<0.001$ unless otherwise indicated.

\section{Supplementary information}

Supplementary information accompanies this paper at https://doi.org/10. 1186/s12865-020-00366-9.

Additional file 1: Supplementary Figure 1. The gate of $C D 4^{+} T$ cells in the thymus (A) or spleen (B) of the WT mice and RelB deficient mice.

Abbreviations

Treg: Regulatory T cells; nTreg: Natural regulatory T cells; tTreg: Thymic regulatory T cells; pTreg: Peripherally regulatory T cells; iTreg: Induced regulatory T cells; PSTAT5: Phosphorylation activator of transcription 5; NFKB: Nuclear factor kappaB; CFSE: Carboxyfluorescein diacetate succinimidyl ester; WT: Wild-type; CTLA-4: Cytotoxic T-lymphocyte-associated protein 4; 
KLRG1: Killer cell lectin-like receptor subfamily G member 1; TIGIT: T-cell immunoglobulin and immune-receptor tyrosine-based inhibitory motif (ITIM) domain; Foxp3: Forkhead box P3; FCS: Fetal calf serum; FACS: Fluorescenceactivated cell sorting.

\section{Authors' contributions}

All authors read and approved the final version of the manuscript. Z. S., Z.M. and L.W. designed and conducted the experiment with cells and analyzed data; W. W, W. Z1, and W. Z2. conducted the experiments with mice and analyzed data; S. Q., L. X., Y. Y., and Z. W. participated in discussions, Z. S. and L.W. contributed to writing the manuscript and participated in discussions.

\section{Funding}

This research was funded by the National Natural Science Foundation of China $(81202293,81274174)$, the science and technology program from Shandong Academy of Medical Sciences (2018-14), Shandong Key Research and Development Project (2019GSF108189) and the Innovation Project of Shandong Academy of Medical Sciences.

\section{Availability of data and materials}

All data is available upon author request.

\section{Ethics approval and consent to participate}

All mice were housed under specific pathogen-free conditions in the animal care facilities at the Institute of Biophysics, Chinese Academy of Sciences and Shandong Academy of Medical Sciences. All experimental procedures were licensed by our local regulatory agency (Shandong Academy of Medical Sciences, Jinan, China, SYXK 20180007).

\section{Consent for publication}

$\mathrm{N} / \mathrm{A}$

\section{Competing interests}

The authors declare that they have no competing interests.

\section{Author details}

${ }^{1}$ Institute of Basic Medicine, Shandong Provincial Hospital Affiliated to Shandong First Medical University, Jinan 250062, China. ${ }^{2}$ Key Laboratory of Infection and Immunity, Institute of Biophysics, Chinese Academy of Sciences, Beijing 100101, China.

Received: 19 March 2020 Accepted: 12 June 2020

Published online: 18 June 2020

\section{References}

1. Abbas AK, Benoist C, Bluestone JA, Campbell DJ, Ghosh S, Hori S, Jiang S, Kuchroo VK, Mathis D, Roncarolo MG, et al. Regulatory T cells: recommendations to simplify the nomenclature. Nat Immunol. 2013;14:307-8.

2. Fu R, Zhang YW, Li HM, LV WC, Zhao L, Guo QL, Lu T, Weiss SJ, Li ZY, Wu ZQ. LW106, a novel indoleamine 2,3-dioxygenase 1 inhibitor, suppresses tumour progression by limiting stroma-immune crosstalk and cancer stem cell enrichment in tumour micro-environment. Br J Pharmacol. 2018;175: 3034-49.

3. Hsieh CS, Zheng Y, Liang Y, Fontenot JD, Rudensky AY. An intersection between the self-reactive regulatory and nonregulatory $T$ cell receptor repertoires. Nat Immunol. 2006;7:401-10.

4. Shevach EM, Thornton AM. tTregs, pTregs, and iTregs: similarities and differences. Immunol Rev. 2014;259:88-102

5. Zheng Y, Rudensky AY. Foxp3 in control of the regulatory T cell lineage. Nat Immunol. 2007:8:457-62

6. Schmidt-Supprian M, Courtois G, Tian J, Coyle AJ, Israel A, Rajewsky K, Pasparakis M. Mature T cells depend on signaling through the IKK complex. Immunity. 2003;19:377-89.

7. Isomura I, Palmer S, Grumont RJ, Bunting K, Hoyne G, Wilkinson N, Banerjee A, Proietto A, Gugasyan R, Wu L, et al. c-Rel is required for the development of thymic Foxp3+ CD4 regulatory T cells. J Exp Med. 2009;206:3001-14.

8. Oh H, Grinberg-Bleyer Y, Liao W, Maloney D, Wang P, Wu Z, Wang J, Bhatt DM, Heise N, Schmid RM, et al. An NF-kappaB transcription-factordependent lineage-specific transcriptional program promotes regulatory $T$ cell identity and function. Immunity. 2017;47:450-65 e5.
9. Chen X, Willette-Brown J, Wu X, Hu Y, Howard OM, Hu Y, Oppenheim JJ. IKKalpha is required for the homeostasis of regulatory $T$ cells and for the expansion of both regulatory and effector CD4 T cells. FASEB J. 2015;29: 443-54.

10. Murray SE. Cell-intrinsic role for NF-kappa B-inducing kinase in peripheral maintenance but not thymic development of Foxp3+ regulatory T cells in mice. PLoS One. 2013;8:e76216.

11. de Lafaille MAC, Lafaille JJ. Natural and adaptive foxp3+ regulatory T cells: more of the same or a division of labor? Immunity. 2009;30:626-35.

12. Kastenmuller W, Gasteiger G, Subramanian N, Sparwasser T, Busch DH, Belkaid Y, Drexler I, Germain RN. Regulatory T cells selectively control CD8+ T cell effector pool size via IL-2 restriction. J Immunol. 2011;187: 3186-97.

13. Joetham A, Takeda K, Taube C, Miyahara N, Matsubara S, Koya T, Rha YH, Dakhama A, Gelfand EW. Naturally occurring lung CD4(+)CD25(+) T cell regulation of airway allergic responses depends on IL-10 induction of TGFbeta. J Immunol. 2007;178:1433-42.

14. O'Sullivan BJ, Pai S, Street S, An X, MacDonald KP, Wong M, Strutton G, Gerondakis S, Steptoe RJ. BF de St Groth, et al: immunotherapy with costimulatory dendritic cells to control autoimmune inflammation. J Immunol. 2011;187:4018-30.

15. Weih F, Carrasco D, Durham SK, Barton DS, Rizzo CA, Ryseck RP, Lira SA, Bravo R. Multiorgan inflammation and hematopoietic abnormalities in mice with a targeted disruption of RelB, a member of the NF-kappa B/Rel family. Cell. 1995:80:331-40.

16. Weih F, Durham SK, Barton DS, Sha WC, Baltimore D, Bravo R. Both multiorgan inflammation and myeloid hyperplasia in RelB-deficient mice are T cell dependent. J Immunol. 1996;157:3974-9.

17. Scheinecker C, McHugh R, Shevach EM, Germain RN. Constitutive presentation of a natural tissue autoantigen exclusively by dendritic cells in the draining lymph node. J Exp Med. 2002;196:1079-90.

18. Baik S, Sekai M, Hamazaki Y, Jenkinson WE, Anderson G. Relb acts downstream of medullary thymic epithelial stem cells and is essential for the emergence of RANK(+) medullary epithelial progenitors. Eur J Immunol. 2016;46:857-62.

19. O'Sullivan BJ, Yekollu S, Ruscher R, Mehdi AM, Maradana MR, Chidgey AP, Thomas R. Autoimmune-mediated Thymic atrophy is accelerated but reversible in RelB-deficient mice. Front Immunol. 2018;9:1092.

20. Li J, Chen S, Chen W, Ye Q, Dou Y, Xiao Y, Zhang L, Minze LJ, Li XC, Xiao X. Role of the NF-kappaB family member RelB in regulation of Foxp3(+) regulatory T cells in vivo. J Immunol. 2018;200:1325-34.

21. del Rio ML, Rodriguez-Barbosa Jl, Kremmer E, Forster R. CD103- and CD103+ bronchial lymph node dendritic cells are specialized in presenting and cross-presenting innocuous antigen to CD4+ and CD8+ T cells. J Immunol. 2007;178:6861-6.

22. Martin E, Capini C, Duggan E, Lutzky VP, Stumbles P, Pettit AR, O'Sullivan B, Thomas R. Antigen-specific suppression of established arthritis in mice by dendritic cells deficient in NF-kappaB. Arthritis Rheum. 2007:56:2255-66.

23. Koliesnik 1O, Andreas N, Thuy A, Sreekantapuram S, Haenold R, Weih F. Alternative NF-kappaB signaling controls peripheral homeostasis and function of regulatory T cells. Immunobiology. 2019;224:687-96.

24. Aschenbrenner K, D'Cruz LM, Vollmann EH, Hinterberger M, Emmerich J, Swee LK, Rolink A, Klein L. Selection of Foxp3+ regulatory T cells specific for self antigen expressed and presented by Aire+ medullary thymic epithelial cells. Nat Immunol. 2007:8:351-8.

25. Coquet JM, Ribot JC, Babala N, Middendorp S, van der Horst G, Xiao Y, Neves JF, Fonseca-Pereira D, Jacobs H, Pennington DJ, et al. Epithelial and dendritic cells in the thymic medulla promote CD4+Foxp3+ regulatory $T$ cell development via the CD27-CD70 pathway. J Exp Med. 2013;210:715-28.

26. Cowan JE, Parnell SM, Nakamura K, Caamano JH, Lane PJ, Jenkinson EJ, Jenkinson WE, Anderson G. The thymic medulla is required for Foxp3+ regulatory but not conventional CD4+ thymocyte development. J Exp Med. 2013;210:675-81.

27. Gondek DC, Lu LF, Quezada SA, Sakaguchi S, Noelle RJ. Cutting edge: contact-mediated suppression by CD4+CD25+ regulatory cells involves a granzyme B-dependent, perforin-independent mechanism. J Immunol. 2005; 174:1783-6.

28. Oderup C, Cederbom L, Makowska A, Cilio CM, Ivars F. Cytotoxic T lymphocyte antigen-4-dependent down-modulation of costimulatory molecules on dendritic cells in CD4+ CD25+ regulatory T-cell-mediated suppression. Immunology. 2006;118:240-9. 
29. Fisson S, Darrasse-Jeze G, Litvinova E, Septier F, Klatzmann D, Liblau R, Salomon BL. Continuous activation of autoreactive CD4+ CD25+ regulatory T cells in the steady state. J Exp Med. 2003;198:737-46.

30. Lee JH, Kang SG, Kim CH. FoxP3+ T cells undergo conventional first switch to lymphoid tissue homing receptors in thymus but accelerated second switch to nonlymphoid tissue homing receptors in secondary lymphoid tissues. J Immunol. 2007;178:301-11.

31. Szanya V, Ermann J, Taylor C, Holness C, Fathman CG. The subpopulation of $\mathrm{CD} 4+\mathrm{CD} 25+$ splenocytes that delays adoptive transfer of diabetes expresses L-selectin and high levels of CCR7. J Immunol. 2002;169:2461-5.

32. Yang H, Zhang Y, Wu M, Li J, Zhou W, Li G, Li X, Xiao B, Christadoss P. Suppression of ongoing experimental autoimmune myasthenia gravis by transfer of RelB-silenced bone marrow dentritic cells is associated with a change from a Thelper Th17/Th1 to a Th2 and FoxP3+ regulatory T-cell profile. Inflamm Res. 2010:59:197-205.

33. Polesso F, Sarker M, Anderson A, Parker DC, Murray SE. Constitutive expression of NF-kappaB inducing kinase in regulatory $T$ cells impairs suppressive function and promotes instability and pro-inflammatory cytokine production. Sci Rep. 2017;7:14779.

34. Dhar A, Chawla M, Chattopadhyay S, Oswal N, Umar D, Gupta S, Bal V, Rath S, George A, Arimbasseri GA, et al. Role of NF-kappaB2-p100 in regulatory T cell homeostasis and activation. Sci Rep. 2019:9:13867.

35. Grinberg-Bleyer Y, Caron R, Seeley JJ, De Silva NS, Schindler CW, Hayden MS, Klein U, Ghosh S. The alternative NF-kappaB pathway in regulatory T cell homeostasis and suppressive function. J Immunol. 2018;200:2362-71.

36. Plaza-Sirvent C, Schuster M, Neumann Y. Heise U, Pils MC, Schulze-Osthoff K. Schmitz: c-FLIP expression in Foxp3-expressing cells is essential for survival of regulatory T cells and prevention of autoimmunity. Cell Rep. 2017;18:12-22.

37. Pierson W, Cauwe B, Policheni A, Schlenner SM, Franckaert D, Berges J, Humblet-Baron S, Schonefeldt S, Herold MJ, Hildeman D, et al. Antiapoptotic Mcl-1 is critical for the survival and niche-filling capacity of Foxp3(+) regulatory T cells. Nat Immunol. 2013;14:959-65.

38. Malek TR, Castro I. Interleukin-2 receptor signaling: at the interface between tolerance and immunity. Immunity. 2010;33:153-65.

39. Sakaguchi S, Ono M, Setoguchi R, Yagi H, Hori S, Fehervari Z, Shimizu J, Takahashi T, Nomura T. Foxp3+ CD25+ CD4+ natural regulatory T cells in dominant selftolerance and autoimmune disease. Immunol Rev. 2006;212:8-27.

40. Shi H, Liu C, Tan H, Li Y, Nguyen TM, Dhungana Y, Guy C, Vogel P, Neale G, Rankin S, et al. Hippo kinases Mst1 and Mst2 sense and amplify IL-2R-STAT5 signaling in regulatory $T$ cells to establish stable regulatory activity. Immunity. 2018;49:899-914 e6.

\section{Publisher's Note}

Springer Nature remains neutral with regard to jurisdictional claims in published maps and institutional affiliations.

Ready to submit your research? Choose BMC and benefit from:

- fast, convenient online submission

- thorough peer review by experienced researchers in your field

- rapid publication on acceptance

- support for research data, including large and complex data types

- gold Open Access which fosters wider collaboration and increased citations

- maximum visibility for your research: over $100 \mathrm{M}$ website views per year

At $\mathrm{BMC}$, research is always in progress.

Learn more biomedcentral.com/submissions 